\title{
Sex workers' accounts of condom use: implications for condom production, promotion and health policy
}

\author{
Caroline Free, Ian Roberts, Megan McGuire
}

\begin{abstract}
Objectives To explore sex workers' accounts of condom use and their recommendations about how condoms might be improved.

Methods In-depth interviews were conducted with 22 female sex workers in sex work premises in London, UK and Amsterdam, The Netherlands.

Results The consistent and effective use of condoms was dependent upon client selection, sex worker control of the condom, communication skills and on condomand sex-related skills. The design of facilities, the way the encounter was structured and alarm call systems were key to generating an environment in which sex worker control of the interaction was feasible. A wide range of practices used for 'safer sex', including the use of simulated vaginal sex, skills in fitting the condom in a sexually arousing way, checking the condom placement during intercourse and holding onto the condom during
\end{abstract}

\section{Introduction}

Consistent condom use can reduce the incidence of HIV and a range of sexually transmitted infections (STIs) including gonorrhoea, trichomonas, syphilis and chlamydia. ${ }^{1}$ However, the effectiveness of condoms in preventing STIs is reduced by inconsistent use, breakage and slippage. Condom breakage or slippage is reported to occur in up to $5 \%$ of episodes of condom use $\mathrm{u}^{2-5}$ and is associated with incorrect condom application. ${ }^{5}$

There has been considerable research on sex workers in the prevention of STIs and HIV. Much of the existing work focuses on the prevalence of HIV, STI or condom use among sex workers and their clients. ${ }^{6-8}$ Sex workers working in brothels report high and increasing levels of condom use with very low levels of breakage or slippage. ${ }^{9-11}$ Reported levels of condom use among streetbased sex workers is much lower. ${ }^{12}$ A number of factors associated with condom non-use among sex workers have been identified, including lack of condom availability, economic pressure, subjective evaluations by sex worker regarding risk and the perception of clients that sex with a condom is less pleasurable. ${ }^{13-17}$ More recent work has highlighted the importance of gatekeeper support for condom use where gatekeepers are defined as those who manage sex workers. ${ }^{15-17}$

The skills used by experienced sex workers to achieve high levels of effective condom use could inform condom promotion interventions but has received little attention. Furthermore, sex workers in some locations may be

Nutrition and Public Health Interventions Unit, Department of Epidemiology and Population Health, London School of Hygiene and Tropical Medicine, London, UK

Caroline Free, PhD, MRCGP, General Practitioner and Clinical Lecturer in Epidemiology

lan Roberts, MRCP, PhD, Professor of Epidemiology

Megan McGuire, MSc, MSc Student

Correspondence to: Dr Caroline Free, Nutrition and Public Health Interventions Unit, Department of Epidemiology and Population Health, London School of Hygiene and Tropical Medicine, Keppel Street, London WC1E 7HT, UK.

E-mail: Caroline.Free@lshtm.ac.uk withdrawal, were described but awareness of such practices was piecemeal. Several sex workers said that particular care is needed when using condoms in men with a small penis and pointed out to the authors that a smaller condom would be useful.

Conclusions The sex workers told us about the importance of environmental factors and a range of sexand condom-related skills in 'safer sex'. Environmental 'safety' features could be addressed through a licensing system for sex work premises. Communication, condomand sex-related skills should be more broadly disseminated through health promotion initiatives with sex workers. The issue of condom fit deserves further attention.

Keywords condom, sex workers, sexual health, sexually transmitted infections

J Fam Plann Reprod Health Care 2007; 33(2): 107-111

(Accepted 26 June 2006)
Key message points

- Most sex workers obtained condoms through health services and wanted smaller condoms to be made available to them.

- Experienced sex workers described communication skills and a number of condom- and sex-related skills to reduce sex risk including the means by which they combined sexual arousal with condom placement and using 'simulated vaginal sex' techniques.

- Safer sex promotion targeting sex workers should incorporate core skills in communication and wider dissemination of additional skills, which can reduce sexual risk.

uniquely placed to draw comparisons in the use of condoms with a large number of different men from a wide range of ethnic backgrounds. Such expertise could have lessons for condom manufacture.

The present study used in-depth interviews with sex workers who consistently used condoms to gain insight into their experience of condom use, the means by which skills were learned and to identify any lessons for condom manufacture and condom promotion.

\section{Methods}

We recruited sex workers in the 'red-light districts' of London. UK and Amsterdam, The Netherlands. Two of the authors (CF and IR) specifically recruited sex workers who were working 'off street'. In London, we usually obtained access to sex workers via a 'maid' who opened the door of the premises. We explained what the study was about and, if access to the sex worker was granted, we explained again to the sex worker concerned. In Amsterdam, we spoke directly to sex workers. We were refused entry to two premises. To preserve anonymity we did not ask sex workers to give written consent. Instead, we signed and numbered a form stating that information had been given to the sex worker. We did not collect demographic data on sex workers but used a topic guide to ensure the same areas were covered in the interviews. We taped and transcribed the interviews. Sex workers from three establishments refused to join the study since they did not wish to be taped. An additional two people who did not want to be taped were included in the study despite refusing to be taped. 
Free et al.

They were interviewed to see if there were differences between the accounts of those who did and did not mind being taped. We made notes during and after these interviews. At the end of the interviews we asked the sex workers for samples of the condoms they used and to show us any lubricants they used. We paid the sex workers to the value of the standard fee for 'straight sex' to compensate for their time and any lost income. The transcripts were read by all authors and a coding framework developed. One author (MM) coded the interviews according to the framework. Data were viewed horizontally to identify the relationships within and between each code. Data collection was continued until no new major themes emerged.

\section{Ethical approval}

Ethical approval for the study was obtained from the London School of Hygiene and Tropical Medicine Ethics Committee.

\section{Results}

We interviewed 22 sex workers. All sex workers reported that they always used condoms with clients for oral or vaginal sex. They reported very few episodes of breakage or slippage. Some sex workers reported that they had never experienced condom breakage during sexual intercourse. Only one sex worker reported having anal sex with clients. Recruitment of sex workers took place in settings where there was a high turnover of clients. Sessions with clients could be as short as 10 minutes, although they were often longer, and sex workers could have up to 20 clients in a day. Themes in the non-taped interviews were similar to those in the taped interviews.

\section{Client refusal}

The ability to select clients was considered a key factor in ensuring consistent condom use (Box 1). Sex workers generally refused clients at the door based on their perceptions of clients' attitudes and behaviour. All the sex workers were able to alert someone if there was a problem with a client either through an alarm or by calling for someone who was 'just upstairs' or 'out the back'

Refusal once the man was admitted to the room occurred less often. Sex workers refused to have sexual intercourse with men who had 'extra large' or 'super-large' penises largely for reasons of comfort rather than concern about a condom breaking. Excellent communication and negotiation skills were required in order to keep the client at least relatively happy if sex was to be refused or an alternative service such as non-penetrative sexual arousal was to be offered.

\section{Condom control, selection and fit}

All condoms used were provided by the sex workers except one sex worker who allowed a 'special regular' client to

\section{Box 1: Client selection}

$\mathrm{R}$ : The first thing, yes, if they look weird I sometimes open the door you know especially because like ... and I listen to how they talk [R13]

R: You see it in the face, you see it on the clothes and you see it when he talks with you. You see he is friendly or unfriendly.

I: Okay.

R: I don't I don't have to take every customer in.

I: Yeah.

R: So l'm my own boss that's why I can look for my customers [R18].
Box 2: Condom selection and fit

R: It's very thick, it's just for work. Really I don't want to use this condom for my partner or my boyfriend [R19].

R: Stretchy yeah, so it stretches, so no matter the size of the penis the condom will go on, you fix it. So no matter how big it is no matter how long it is it's going [R11].

R: How make a condom better. OK. This condom is OK it's good ... there are some people with small penis, either way there are times the condom cannot, it's like it's too big for them, even though the penis is very strong, so if the condom makers want to maybe like improve the condom market they should make condom for one that's smaller than this.

I: A smaller condom.

R: Yeah that's a good idea for penis that is small.

: So what you say, there's no problem with big penises but smaller penises?

$\mathrm{R}$ : Smaller penis even when, even when it's strong it does not fix it [R11].

$\mathrm{R}$ : Condoms come off with Chinese men [R1]

$\mathrm{R}$ : So it's a problem if the, the end of the penis is ... small and it gets wider towards the base.

I: Yeah.

R: That, that's a problem [R4].

R: I want to find, but I don't know where, a condom for Chinese because... this one is very big for Chinese people. No I don't know where I can find a small size. I think it's not possible.

I: Okay so what do you do then if you can't find a small size?

R: I can er use that one but I need to be double careful [R13].

bring his own (Box 2). Most sex workers used condoms obtained from health clinics or health promotion workers although some bought their own. Condom selection reflected personal preferences regarding taste, thickness and elasticity. Most of the condoms were standard width $(52 \mathrm{~mm})$ and ranged in length from 192 to $209 \mathrm{~mm}$. One sex worker had a smaller flavoured condom, which she used for oral sex and for men with a smaller penis (width $49 \mathrm{~mm}$, length $196 \mathrm{~mm}$ ) and a larger condom for use with men with a larger penis (width $54 \mathrm{~mm}$, length $220 \mathrm{~mm}$ ). She stated that a normal condom with a large penis was not a problem provided you used lubricant.

Sex workers reported that penis size varied much more between individuals than between different ethnic groups. From the sex workers' perspective a large penis was not generally a problem for condom use. Some had never had a problem with a penis that was too big for a condom. One sex worker reported that on three or four occasions they had encountered a client for whom the condom was 'genuinely' too tight at the bottom. Other sex workers acknowledged that the condom might be a little tight for a few men but this did not cause the sex worker concern. Clients' complaints about condom tightness were not, in the assessment of the sex worker, always related to penis size.

In contrast, a number of the sex workers pointed out that a condom could come off a man who had a small penis and in such situations that they had to take extreme care holding on to the condom. Sex workers reported that men of any racial appearance could have a small penis but it was common in 'Chinese' men, as distinct from men from Asia, Southeast Asia, Japan or any other specific Asian country. Sex workers suggested that a smaller condom would be useful. Two sex workers noted that although it didn't happen that often, the shape of the penis could be important. Specifically, if the penis was long and thin or tapering so that it was wider at the base than the top then there was a particular need to hold on to the condom during sex. 


\section{Using the condom and 'safer' sex}

After securing the fee, condom placement was invariably the first task undertaken by the sex worker. In order to ensure effective condom use, good communication skills and skills in sexual arousal were as important as technical skills or practices such as correct condom placement, use of lubricant, checking the condom during sex and holding onto the condom during withdrawal (Box 3). Sex workers did not allow the man to touch the condom since they were concerned that clients might deliberately break the condom.

Many clients already had an erection immediately prior to condom placement, but the absence of an erection was not seen as an obstacle to condom placement. Several sex workers described how they made the act of putting the condom on sexually arousing so that stimulation of a full erection and condom placement occurred simultaneously. This involved penis stimulation with the hand or mouth. In the latter, the condom is put on the head of the flaccid penis, oral stimulation begins, taking care that the mouth only touches the condom, and the condom is rolled down as the penis enlarges. Sex workers described their clients as often being nervous, and putting the condom on in an arousing or fun way was an important aspect of ensuring compliance with condom use. One sex worker described how she used oral sex to put on the condom without the client seeing the condom or being aware that she was putting it on.

Correct condom placement was important and included following standard advice about condom placement and withdrawal such as putting the condom on the right way

\section{Box 3: Condom use}

R: ... and some people they like to break the condom. So that's why I say don't touch the condom. Never a customer touched my condom [R18].

Putting the condom on in a sexually arousing way:

R: Some, some, some men they're not enough hard.

I: Yeah.

$\mathrm{R}$ : It is problem to put in the condom.

I: Yes.

R: Yeah.

I: So what, what do you do then?

R: Erm I and I u use my hand, yeah, use my finger, yeah, to touch, to touch slowly, slowly, get the feeling [R1]

$\mathrm{R}$ : I mean some girls they can do it with their mouths.

I: Yeah.

$\mathrm{R}$ : So you know they like $t$ tip in very ... they they take the tip in the mouth.

I: Yeah.

R: .... and then they just go on the mouth and then they slowly roll it down [R15].

R: I just put the thing [condom] in my mouth and slide it down ... Mm yeah I breathe the penis in while, while sliding it down, makes it..

I: It extends the condom into the back of your mouth?

$\mathrm{R}$ : $M m \mathrm{~mm}$ while getting the penis hard, if it's soft you know?

I: And then and then you move your mouth forwards.

$\mathrm{R}$ : Yes and then I can already instantly blow, put the condom on. So he doesn't really see the condom, you know, because that's a bit of a turn off [R14].

Correct condom placement:

R: Yeah there's a definite direction to fit the condom [R11]

$\mathrm{R}$ : If someone is not circumcised you pull the foreskin back.

$\mathrm{R}: \mathrm{Mm}$.

I: And then you put the condom over the top.

R: Just you make sure you squeeze [the air out].

I: Yeah.

$\mathrm{R}$ : And just pull it over ... all the way to the end.

I: Yeah.

$\mathrm{R}$ : Then you make sure there's no air. If there is air you just do it like this and hold [R15].

\section{Box 4: Techniques to stop breakage and slippage}

$\mathrm{R}$ : I've worked maybe altogether 3 years and it's happened maybe two times that its broke ... you know not after they finish luckily. But that's been when it's been very very dry, when, you know they take a long time. But the [important] thing is the gel [R13].

I: So has that [condom breakage] ever happened to you?

R: No, because I use a lot of gel.

$\mathrm{I}$ : And so it's never happened to you?

R: No never.

I: And what and has ... have you ever had an experience where the condoms slipped?

$\mathrm{R}$ : No because I always have my hand there so it cannot slip [R11].

$\mathrm{R}$ : There is one thing you always have to do.

I: Yeah.

$\mathrm{R}$ : When the man is finished you take ... and he pulls out the penis, always hold the condom, because sometimes when a man finish, then all of a sudden it's like, you know, it's soft.

I: Yeah.

$\mathrm{R}$ : The penis goes soft with some men

I: Yeah.

$\mathrm{R}$ : And then because there is juice inside then it might go slippery, so you always make sure when you take out the penis.

I: Yeah.

R: You always hold the condom.

I: Yeah.

R: Because or else it might, you know stay inside [R15].

R: Well normally I go under and the man goes on top, but always I hold the condom with my hands, so you are always sure.

l: Always.

R: Always

I: Throughout?

R: Yeah [laughs] [R17].

$\mathrm{R}$ : I squeeze the penis and I feel if the condom is on ... I mean I don't do it constantly I just check from time to time [R1].

round, removing the air, rolling the condom all the way down and holding onto the condom during withdrawal (which took place immediately after the man had had ejaculated). The importance of pulling the foreskin back before condom placement was noted. Several sex workers described putting the condom on the penis by stretching it apart with their fingers, placing it over the penis and then getting rid of the air. Sex workers repeatedly emphasised the importance of lubricant to increase their comfort and to reduce breakage and slippage (Box 4). They attributed episodes of condom breakage to insufficient lubricant. All the lubricants used were water-based. Sex workers also carried out additional practices to ensure 'safe' condom use. During intercourse some sex workers described holding on to the condom continuously whilst others intermittently checked the condom was still in place. During sex, if the man began to lose his erection, sex workers used techniques such as hand stimulation. Sex workers reported some difficulties with men who tried to continue having sex after ejaculation. A few sex workers in London reported that some men were able to, and hence tried to, ejaculate a second time (for the same price as one and in the same condom). Both these practices were considered risky in terms of condom breakage and slippage. Again good communication skills were required in insisting on and instigating withdrawal to avoid escalating any conflict within the interaction. One sex worker reported that some men have a lot of pre-ejaculate which can result in the condom slipping and another had safer sex by stopping vaginal intercourse before ejaculation and using manual stimulation to effect ejaculation. Removal and disposal of the condom was carried out by either the client or sex worker using a tissue. After the client had left, sex workers reported washing to ensure cleanliness. 
Free et al.

Three sex workers in Amsterdam reported practising 'safer sex' by simulating vaginal intercourse. The technique involved using a condom, plenty of lubricant and putting the penis into a cupped hand, resulting in a satisfied customer who was reportedly not aware of not having had vaginal sex.

Sex workers reported receiving instructions on condom use from health clinics and health promotion workers. Other communication and sexual skills fundamental to the practice of safer sex were learned through informal networks with other sex workers or from maids or from personal experience. It was notable that whilst a broad range of communication, sexual arousal and technical skills were reported, not all the sex workers interviewed were aware of the full range of skills. For example, whilst one sex worker reported almost never having sexual intercourse with clients as she used simulated vaginal sex without clients realising, others were unaware or unskilled in such practices.

\section{Discussion}

The sex workers we interviewed were experienced in using condoms. They had sex with up to 20 clients in a day, reported always using condoms, and breakage or slippage was very unusual. Sex workers reported being in control of the interaction, having the ability to refuse clients and being in charge of all aspects of condom use. Being located in a building, the design of facilities, the way the encounter was structured and alarm call systems were key to generating an environment in which sex worker control of the interaction was feasible. Sex workers told us about a range of sex- and condom-related skills. These included well-known factors such as correct condom placement, use of lubricant, fitting the condom in a sexually arousing way and holding on to the condom during withdrawal. ${ }^{18-20}$ They also described techniques previously described in the manual Making Sex Work Safe, such as checking the condom during intercourse, fitting the condom in a sexually arousing way so as to cause an erection, checking the condom during intercourse, and simulated vaginal sex. ${ }^{21}$ To our knowledge these factors have not previously been reported in the peer-reviewed academic literature. Sex workers recommended that a smaller condom would be useful in improving the effectiveness of their condom use. Excellent communication skills and skills combining condom placement with sexual arousal were as important in ensuring safer sex as technical skills in correct condom placement.

Sex workers in this study were all recruited from brothels where many of the gatekeepers were reported to be supportive of condom use. Establishments within the immediate vicinity of the brothels from which we sampled all reported using condoms and there was a standard price for sex. This, together with a ready availability of clients, may have limited the economic pressure for condom non-use. The findings and implications may not be relevant to other settings such as where economic pressure is greater or for street-based sex work. Furthermore, we do not claim that these results reflect the practice of sex workers in other settings, nor are we suggesting that all sex workers are experienced in using condoms. Indeed, sex workers in some settings have high rates of STIs. ${ }^{22} \mathrm{We}$ also acknowledge that these findings are very unlikely to be relevant to sex work linked to trafficking. 23

The impact of environmental factors in facilitating sex worker control of the interaction and safer sex was key to the practice of safer sex. This finding supports the view that current government strategy to reject licensing of sex work premises may be counterproductive for sex workers' health and safety. ${ }^{24}$ The provision of such environmental 'safety' features could form part of a prerequisite for licensing of premises.

In this setting, core skills in communication and negotiation were key to securing personal safety and condom use without putting off clients. The findings suggest that key communication, sexual and condom skills required for safer sex work should be more broadly disseminated through health promotion initiatives. Knowledge and skills that result in safer practices such as combining condom placement with sexual arousal and simulated vaginal sex may most appropriately be taught by those with sex work experience.

The World Health Organization (WHO) recommends condoms with a flat width of $53 \mathrm{~mm}, 49 \mathrm{~mm}$ and, in the most recent guidance, a larger condom (up to $56 \mathrm{~mm}$ ) 'depending on condom promotion settings'. ${ }^{25}$ In the past, condoms of $49 \mathrm{~mm}$ width were specifically recommended for Asia. Sex workers' accounts were in keeping with the modified guidance in that they reported greater variance in penis size between men of the same ethnic background than between ethnic groups. Sex workers accounts were not entirely in keeping with WHO guidance in that they did not generally encounter difficulties with condom fit with men from Asia or Southeast Asia but specifically reported a problem with condom fit for 'Chinese' men. This may relate to the specific Asian groups that were clients of these sex workers. Sex workers, however, suggested that the availability of smaller condoms could result in better condom fit and might improve condom efficacy. Men using sex workers are derived from the general population. Having a smaller condom available might therefore also increase the effectiveness of condom use in the general population, although sensitivity in marketing such a condom would be required.

\section{Conclusions}

The design of facilities, the structure of the encounter and alarm call systems were important in creating an environment in which safer sex could be practised by sex workers. Sex workers describe using a broad range of communication, sexual and condom use skills in ensuring safer sex but awareness of the whole range of skills was piecemeal. Greater dissemination of core communication, sexual and condom use skills described in this paper could usefully be afforded through health promotion programmes with sex workers. Such a strategy should not negate the importance of addressing economic, socio-structural and environmental factors including gatekeeper support, which are key to determining condom use among sex workers. Some condom-related skills described may be relevant to the promotion of safer sex in non-commercial settings. The issue of the provision of different size condoms deserves further attention.

Authors' note

In all the quotes in Boxes 1-4, slang terms for 'penis' that might cause offence to readers have been changed to 'penis'. Also, 'R' (together with the respondent number) indicates the respondents' comments and ' $\mathrm{l}$ ' denotes the interviewers' questions and/or responses.

\section{Acknowledgements}

The authors would like to thank all the sex workers they interviewed. They would also like to thank Debbie Swift, Sara Christensen and Marion Haberhauer for transcribing the interviews.

Statements on funding and competing interests Funding None identified.

Competing interests None identified. 
References

1 Holmes K, Levine R, Weaver L. Effectiveness of condoms in preventing sexually transmitted infections. Bull World Health Organ 2004; 82: 454-461.

2 Boldsen JL, Jeune B, Madsen PC. Aspects of comfort and safety of condom. A study of two thousand intercourses among volunteer couples. Scand J Soc Med 1992; 20: 247-252.

3 Mekonen E, Mekonen A. Breakage and slippage of condoms among users in north Gondar Province, Ethiopia. East Afr Med J 1999; 76: 481-483.

4 Messiah A, Dart T, Spencer BE, Warszawski J. Condom breakage and slippage during heterosexual intercourse: a French national survey. French National Survey on Sexual Behavior Group (ACSF). Am J Public Health 1997; 87: 421-424.

5 Spruyt A, Steiner M, Joanis C, Glover L, Piedrahita C, Alvarado $\mathrm{G}$, et al. Identifying condom users at risk for breakage and slippage: findings from three international sites. Am J Public Health 1998; 88: 239-244.

6 Ward H, Day S, Green A, Cooper K, Weber J. Declining prevalence of STI in the London sex industry, 1985 to 2002. Epidemiol Community Health 2005; 59: 22

7 Brahme R, Mehta S, Sahay S, Joglekar N, Ghate M, Joshi S, et al. Correlates and trend of HIV prevalence among female sex workers attending sexually transmitted disease clinics in Pune, India (1993-2002). J Acquir Immune Defic Syndr 2006; 41: 107-113.

8 Wong M, Chan R, Koh D, Barrett M, Chew S, Wee S. A comparative study of condom use and self-reported sexually transmitted infections between foreign Asian and local clients of sex workers in Singapore. Sex Transm Dis 2005; 32: 439-445.

9 Krogsgaard K, Gluud C, Pedersen C, Nielsen JO, Juhl E, Gerstoft J, et al. Widespread use of condoms and low prevalence of sexually transmitted diseases in Danish nondrug addict prostitutes. BMJ 1986; 293: 1473-1474.

10 Cusick L. Non-use of condoms by prostitute women. AIDS Care 1998; 10: 133-146.

11 van Haastrecht $H$, Fennema J, Coutinho $R$, van der Helm $T$, van den Hoek JA. HIV prevalence and risk behaviour among prostitutes and clients in Amsterdam: migrants at increased risk for HIV infection. Genitourin Med 1993; 69: 251-256.

12 Fornasca C, Gai F, Tarantello M, Gallina P. Knowledge of sexually transmitted diseases and condom use among female street sex workers in Padua. Acta Dermatovenerol Alp Panonica Adriat 2005; 14: 107-110.

13 Wang B, Li X, Stanton B, Yang H, Fang X, Zhao R, et al. Vaginal douching, condom use and sexually transmitted infections among Chinese female sex workers. Sex Transm Dis 2005; 32: 696-702

14 Sopheab H, Fylkesnes K, Vun MC, O'Farrell N. HIV-Related risk behaviours in Cambodia and effects of mobility. $J$ Acquir Immune Defic Syndr 2006; 41: 81-86.

15 Basuki E, Wolffers I, Deville W, Erlaini N, Luhpuri D, Hargono $\mathrm{R}$, et al. Reasons for not using condoms among female sex workers in Indonesia. AIDS Educ Prev 2002; 14: 102-116.

16 Nemoto $T$, Iwamoto $M$, Oh H, Wong S, Nguyen H. Risk behaviours among Asian women who work at massage parlours in San Francisco: perspectives from masseuses and owners/managers. AIDS Educ Prev 2005; 17: 444-456.

17 Yang H, Li X, Stanton B, Fang X, Zhao R, Dong B, et al. Condom use among female sex workers in China: role of gatekeepers. Sex Transm Dis 2005; 32: 572-580.

18 Saunders S, Graham C, Yarber W, Crosby R. Condom use errors and problems among young women who put condoms on their male partners. J Am Med Womens Assoc 2003; 58 : 95-98.

19 de Graaf R, Vanwesenbeeck I, van Zessen G, Straver C, Visser $J$. The effectiveness of condoms in heterosexual prostitution in The Netherlands. AIDS 1993; 7: 265-269.

20 Gabbay M, Gibbs A. Does additional lubricant reduce condom failure? Contraception 1996; 53: 155-158.

21 Network of Sex Work Projects. Making Sex Work Safe. 1999 (updated 2006). http://www.nswp.org/safety/msws/msws01.html [Accessed 25 May 2006].

22 Ruxrungtham K, Brown T, Phanuphak P. HIV/AIDS in Asia. Lancet 2004; 364: 8213-8215.

23 Busza J, Castle S, Diarra A. Trafficking and health. BMJ 2004; 328: 1369-1371.

24 Boynton P, Cusick L. Sex workers to pay the price. BMJ 2006; 332: 190-191.

25 World Health Organization (WHO). The Male Latex Condom: Specifications and Guidelines for Condom Procurement. Geneva, Switzerland: WHO/UNAIDS/UNFPA/FHI/SHR, 2004.

\section{Patients denied access to sexual} health clinics

People seeking contraceptive care, health screening, or STI testing could be experiencing reductions to choice and care. New research published by the Faculty of Family Planning and Reproductive Health Care (FFPRHC) highlights disinvestment by PCTs, poor IT systems and lack of training for health professionals

The results of the Faculty's Community Contraceptive Services Questionnaire (which gathered information from 129/207 service leads of community contraceptive services in the UK) highlight cuts to out-of-hours services and recruitment freezes, which are contributing to a reduction in patient access, choice and convenience. This is despite the Government's insistence that sexual health care is a priority.

The main findings of the research, which was carried out within community sexual and reproductive health $(\mathrm{SRH})$ services, and in conjunction with the Department of Health's own mapping exercise of contraceptive services, state:

- $40 \%$ of SRH clinics are having to reduce services, either by closing walk-in sessions when full, accepting only a fixed number of patients or only seeing people with urgent problems.

- Only 4/129 services reported increased funding available to implement long-acting reversible contraception (LARC) provision, despite the NICE clinical guideline on
LARC, which promotes choice for women through increasing access to quality services providing LARC methods.

- Only 5\% of community service leads reported computerised data collection across all clinic sites when asked about data and IT systems. This exposes failures within the NHS to monitor work being done within community SRH services, which is inconsistent with the Government's Payment By Results scheme.

The Community Contraceptive Services Questionnaire can be accessed on the Faculty's website at www.ffprhc.org.uk.

\section{Look after your bones}

Protecting your bones isn't just about checking your calcium levels. There are many other factors that put you at risk of osteoporosis, including your vitamin D intake and exercise pattern. What is most important is that your overall lifestyle is a bone-friendly one. In the Winter 2006/7 issue of The Menopause Exchange Newsletter, registered dietitian Tanya Haffner has plenty of advice on leading a bone-friendly lifestyle. In her article she covers various topics including calcium, vitamin $\mathrm{D}$ and vitamin $\mathrm{K}$, healthy eating, phytoestrogens and suitable forms of exercise.

For more information contact The Menopause Exchange, PO Box 205, Bushey, Herts WD23 1ZS, UK. Tel: +44 (0)20 84207245. E-mail:norma@menopause-exchange.co.uk.

\section{Clinical review of HPV}

The website http://www.medscape.com provides nformation and self-test questions on a range of topics. It is free to register, and it currently has a series of topics on HPV.

- A clinical review on best practices in diagnosis and management of HPV and genital warts.

- News item on HPV vaccination and vulval cancer.

- Interactive case on different perspectives in HPV management.

- Article on cervical HPV screening among older women.

Reported by Henrietta Hughes, MRCGP, DFFP General Practitioner, London, UK

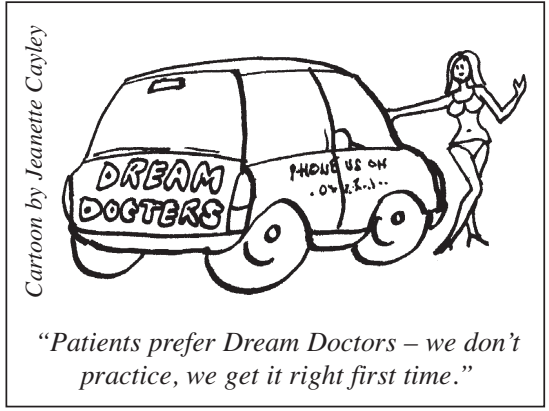

